\title{
Polymorphisms of 5,10-methylenetetrahydrofolate reductase and thymidylate synthase in squamous cell carcinoma and basal cell carcinoma of the skin
}

\author{
SANG YOON KANG ${ }^{1}$, SUNG JUN LEE ${ }^{2}$, SEUNG HO HONG ${ }^{3}$, YOON KYU CHUNG ${ }^{2}$, \\ HYUN SOO OH${ }^{1}$, SUG WON KIM ${ }^{2}$, DONG JIN YIM ${ }^{4}$ and NAM KEUN KIM ${ }^{4,5}$ \\ ${ }^{1}$ Department of Plastic and Reconstructive Surgery, School of Medicine, Kyung Hee University, Seoul; \\ ${ }^{2}$ Department of Plastic and Reconstructive Surgery, Wonju College of Medicine, Yonsei University, Wonju; \\ ${ }^{3}$ Department of Science Education, Teachers College, Jeju National University, Jeju; ${ }^{4}$ Institute for Clinical Research; \\ ${ }^{5}$ Department of Biomedical Science, School of Medicine, CHA University, Seongnam, Korea
}

Received March 12, 2010; Accepted June 24, 2010

DOI: $10.3892 / \mathrm{mmr} .2010 .329$

\begin{abstract}
Genetic instability resulting from mutations in repair genes, defects in folic acid metabolism or DNA synthesis has been reported to contribute significantly to the development of skin cancer. The enzymes 5,10-methylenetetrahydrofolate reductase (MTHFR) and thymidylate synthase (TS) are essential participants in folic acid metabolism and DNA synthesis. Thus, the present case-control study was conducted to determine whether an association exists between the MTHFR/TS polymorphisms and squamous cell carcinoma (SCC) and/or basal cell carcinoma (BCC) among Korean individuals. The study subjects comprised 95 patients with SCC, 100 patients with BCC and 207 controls with no evidence of malignancy or pre-malignant lesions. Patients with skin cancer and control samples were analyzed for polymorphisms of the MTHFR or $T S$ genes by means of polymerase chain reaction-restriction fragment length polymorphism. The MTHFR $677 \mathrm{C}>\mathrm{T}$ and MTHFR 1298A >C polymorphisms showed no significance with regard to the development of SCC and BCC. However, within the $6 \mathrm{bp}$ insertion (ins)/deletion (del) polymorphism in the 3'-untranslated region (3'-UTR) of the TS gene, the BCC group showed statistical significance with a 2.8-fold increased risk of cancer development [adjusted odds ratio $(\mathrm{AOR})=2.821$ ] in heterozygous mutations ( $0 \mathrm{bp} / 6 \mathrm{bp}), 7.5$-fold (AOR=7.539) in homozygous mutations (6 bp/6 bp) and 3-fold ( $\mathrm{AOR}=3.079)$ upon combination of heterozygous mutations and homozygous mutations $(0 \mathrm{bp} / 6 \mathrm{bp}+6 \mathrm{bp} / 6 \mathrm{bp})$. We thus conclude that the $6 \mathrm{bp}$ ins/del polymorphism in the 3 -UTR is associated
\end{abstract}

Correspondence to: Dr Nam Keun Kim, Institute for Clinical Research, Bundang CHA Medical Center, School of Medicine, CHA University, Seongnam 463-712, Korea

E-mail:nkkim@cha.ac.kr; namkkim@naver.com

Key words: squamous cell carcinoma, basal cell carcinoma, skin, methylenetetrahydrofolate reductase, thymidylate synthase with increased risk of the development of skin cancer among Korean individuals with BCC.

\section{Introduction}

Skin cancers such as basal cell carcinoma (BCC) and squamous cell carcinoma (SCC) are reported to occur as a consequence of genetic instability that includes mutations in repair genes, defects in folic acid synthesis or DNA synthesis. Mutations resulting in such genetic instability modify protein synthesis and function, as well as the capacity for repairing DNA damage, thereby inducing a carcinogenic effect (1).

5,10-methylenetetrahydrofolate reductase (MTHFR), located on chromosome $1 \mathrm{p} 36.3$, is involved in the metabolic process of methionine synthesis by means of homocysteine after converting 5,10-methylenetetrahydrofolate into 5-methylenetetrahydrofolate, and either suppresses or increases the likelihood of carcinogenesis. Hypomethylation of DNA resulting from the functional decline of MTHFR gives rise to oncogenes such as $c$-myc and $c$-N-ras, and leads to defects in DNA synthesis and repair (2). It also potentiates DNA synthesis and repair through a folate co-factor, thus preventing uracil misincorporation and double-strand breaks (3). The processes of methylation as well as DNA synthesis and repair are secured with the assistance of such mutual complementary interactions.

Mutations of the MTHFR gene include polymorphisms of $677 \mathrm{C}>\mathrm{T}$ with an alanine (A) to valine (V) substitution and 1298A $>C$ with a glutamate $(G)$ to alanine (A) substitution (4). The 677 TT homozygous variants have only $30 \%$ the activity of the normal enzyme, while the heterozygous variants retain $65 \%$ of normal activity $(5,6)$. On the other hand, a homozygous variant, $1298 \mathrm{CC}$, retains only $40 \%$ of its enzymatic activity compared to 1298AA (7). As a result, the accumulation of homocysteine that is not converted to methionine leads to defects in methionine synthesis, DNA methylation and dTMP synthesis $(8,9)$. This consequently increases the risk of the development of various vascular diseases (10), stomach cancer (11) and esophageal cancer (12). By contrast, such defects have 
been reported to act against the development of hepatocellular carcinoma, colon cancer (13) and acute lymphoblastic leukemia (14).

Thymidylate synthase (TS), located on the short arm of chromosome 18 , is an enzyme responsible for the transformation of dUMP into dTMP during the process of converting 5,10-methylene-tetrahydrofolate into 5-methylenetetrahydrofolate. It therefore acts as a co-factor in folic acid metabolism as well as DNA synthesis (15-18). The untranslated region (UTR) of the TS gene is known to play an important role in transcription and translocation (19-22).

TS is characterized by 3 polymorphisms: its 5'- and 3'-UTR, which are a variable number of tandem repeats, a G/C SNP in the TS enhance region (TSER) and a 3'-UTR 1494 6 bp insertion (ins)/deletion (del) mutation. All three polymorphisms pertain to the expression of the TS gene (23-25). The 3'-UTR 14946 bp ins/del mutation in particular is related to the long-term stability of mRNA. Mutations in the TS gene lead to an accumulation of homocysteine, a decrease in methionine synthesis and a subsequent decrease in TS levels due to a defect in dTMP synthesis. This results in a single or double-strand break depletion through uracil misincorporation (26). Some researchers have reported that dysfunctional TS increases the risk of colon cancer, non-Hodgkin's lymphoma and breast cancer (27-29), and found that TS gene expression in malignant melanoma was considerably increased compared to normal controls.

In view of the key roles that MTHFR and TS play in the occurrence of skin cancer, we performed an association study between polymorphisms of the MTHFR and TS genes and skin cancer.

\section{Materials and methods}

Study subject. The case group comprised 195 patients (mean age \pm SD $69.13 \pm 12.6$ years; range $36-94$ ) with non-melanoma skin cancer recruited from the Department of Plastic and Reconstructive Surgery of Yonsei Wonju Christian Hospital and the Department of Plastic and Reconstructive Surgery of Bundang CHA Medical Center between January 1998 and March 2006. Of these patients, 100 were pathologically diagnosed with BCC and the other 95 with SCC. The control group consisted of 207 individuals (mean age \pm SD 46.42 \pm 16.6 years; range 21-85) without any history of pre-malignant skin lesions or other malignant disorders randomly selected from the visitors to the Bundnag CHA Medical Center. The institutional review board of Bundang CHA Medical Center approved this genetic study. All the patients and controls were Korean and gave their informed consent prior to enrollment in the study.

Genetic analysis. Genomic DNA was extracted from anti-coagulated peripheral blood using the G-DEX blood extraction kit (Intron, Seongnam, Korea). Nucleotide changes in the MTHFR $677 \mathrm{C}>\mathrm{T}$ and 1298A $>\mathrm{C}$ genotypes were determined by polymerase chain reaction-restriction fragment length polymorphism (PCR-RFLP) analysis using isolated genomic DNA as a template. The polymorphisms were identified following the digestion of amplified DNA with the endonucleases HinfI and Fnu4HI for the MTHFR $677 \mathrm{C}>\mathrm{T}$ and
1298A $>$ C polymorphisms. The ins/del polymorphism in the 3'-UTR of the TS gene was classified as 6 bp or 0 bp according to a 6 bp insertion or deletion after DraI digestion. Primers and PCR conditions for each polymorphism analysis were as described previously $(5,30)$.

Statistical analysis. The $\chi^{2}$ test was used to compare allele and genotype frequencies between the case and control groups and to test for Hardy-Weinberg equilibrium. To measure the strength of the association between genotype frequencies and the case group, odds ratios (ORs) and 95\% confidence intervals (CIs) were used. For multivariate analysis, logistic regression was used, adjusted for the effects for possible confounders (age, gender, number of cigarettes smoked per day, occupation and duration of sun exposure per day). Statistical significance was accepted at the $\mathrm{p}<0.05$ level. Analysis was performed using SPSS for Windows version 11.0 (SPSS Inc., Chicago, IL, USA) and SNPAlyze ${ }^{\mathrm{TM}}$ version 5.10 (Dynacom Co., Ltd., Yokohama, Japan).

\section{Results}

MTHFR $677 C>T$ and 1298A $>C$ polymorphisms. No significant association was found between the risk of the development of BCC or SCC and the MTHFR $677 \mathrm{C}>\mathrm{T}$ and $1298 \mathrm{~A}>\mathrm{C}$ polymorphisms in comparison to the control group. The adjusted odds ratio (AOR) values, adjusted to age, gender, smoking history, occupation and duration of sun exposure, showed no statistical significance (Tables I and II). However, the MTHFR $677 \mathrm{C}>\mathrm{T}$ mutation had the tendency to suppress the development of SCC, while MTHFR 1298A>C mutation tended to promote the occurrence of SCC. Heterozygous mutation of MTHFR $677 \mathrm{C}>\mathrm{T}$, in comparison to its homozygous mutation, served to suppress SCC carcinogenesis by $70 \%$ (AOR=0.304, 95\% CI 0.07-1.25), while the overall (CT+TT) genotype showed an overall suppression of carcinogenesis by $50 \%(\mathrm{AOR}=0.516,95 \%$ CI $0.21-1.25)$.

A combination analysis of the MTHFR $677 \mathrm{C}>\mathrm{T}$ and MTHFR 1298A >C polymorphisms did not reveal statistically significant differences in either SCC or BCC (Tables I and II). However, in SCC, combined genotypes of 677CC+1298AC, 677CT+1298AA and 677TT+1298AA $(\mathrm{AOR}=0.538,0.281$ and 0.146 ; $95 \%$ CI 0.12-2.34, 0.07-1.19 and 0.02-1.00, respectively) suppressed carcinogenesis with marginal significance. The combined genotype of 677TT+1298AA had a suppressive effect against SCC (Table I). Although no statistically significant difference was found in $\mathrm{BCC}$, the combined genotypes of 677CC+1298AC, 677CT+1298AA and 677TT+1298AA $(\mathrm{AOR}=0.206,0.399$ and $0.350 ; 95 \%$ CI $0.03-1.23,0.14-1.11$ and $0.09-1.32$, respectively) tended to reduce the risk of cancer by $>60 \%$ in comparison to the genotype $677 \mathrm{CC}+1298 \mathrm{AA}$ (Table II).

$6 \mathrm{bp}$ ins/del polymorphism in the 3'-UTR of the TS gene. Although the TS 3'-UTR 6 bp ins/del polymorphism in SCC showed no statistical significance compared to the control group (Table III), it significantly increased the risk of BCC by 2.8 -fold $(\mathrm{AOR}=2.821)$ in heterozygous variants, 7-fold $(\mathrm{AOR}=7.539)$ in homozygous variants and 3 -fold $(\mathrm{AOR}=3.079)$ with the combination of the variants $(0 \mathrm{bp} / 6 \mathrm{bp}+6 \mathrm{bp} / 6 \mathrm{bp})$. 
Table I. Polymorphisms of MTHFR 677C $>$ T and MTHFR 1298A $>$ C in squamous cell carcinoma.

\begin{tabular}{|c|c|c|c|c|c|}
\hline \multirow{2}{*}{$\begin{array}{l}\text { Genotype } \\
677 \mathrm{C}>\mathrm{T}\end{array}$} & Controls $(\%)$ & Cases (\%) & \multirow[t]{2}{*}{ OR $(95 \% \mathrm{CI})$} & \multicolumn{2}{|c|}{$\operatorname{AOR}(95 \% \mathrm{CI})^{\mathrm{a}}$} \\
\hline & & & & & \\
\hline $\mathrm{CC}$ & 71 (34.3) & $40 \quad(42.1)$ & - & & - \\
\hline $\mathrm{CT}$ & $106 \quad(51.2)$ & $44 \quad(46.3)$ & $0.737(0.44-1.24)$ & 0.590 & $(0.24-1.47)$ \\
\hline $\mathrm{TT}$ & $30 \quad(14.5)$ & 11 (11.6) & $0.651(0.30-1.44)$ & 0.304 & $(0.07-1.25)$ \\
\hline $\mathrm{CT}+\mathrm{TT}$ & $136 \quad(65.7)$ & $55 \quad(57.9)$ & $0.718(0.44-1.18)$ & 0.516 & $(0.21-1.25)$ \\
\hline \multicolumn{6}{|l|}{$1298 \mathrm{~A}>\mathrm{C}$} \\
\hline $\mathrm{AA}$ & $149(72.0)$ & $60 \quad(63.2)$ & - & & - \\
\hline $\mathrm{AC}$ & $54 \quad(26.1)$ & $35 \quad(36.8)$ & $1.610(0.96-2.71)$ & 1.737 & $(0.69-4.38)$ \\
\hline $\mathrm{CC}$ & $4 \quad(1.9)$ & $0 \quad(0.0)$ & $0.275(0.02-5.18)$ & & - \\
\hline $\mathrm{AC}+\mathrm{CC}$ & $58 \quad(28.0)$ & $35 \quad(36.8)$ & $1.499(0.90-2.51)$ & 1.585 & (0.64-3.93) \\
\hline \multicolumn{6}{|c|}{$677 \mathrm{C}>\mathrm{T} / 1298 \mathrm{~A}>\mathrm{C}$} \\
\hline CC/AA & 38 (18.4) & $23 \quad(24.2)$ & - & & - \\
\hline $\mathrm{CC} / \mathrm{AC}$ & $29(14.0)$ & 17 (17.9) & $0.969(0.44-2.14)$ & 0.538 & $(0.12-2.34)$ \\
\hline $\mathrm{CC} / \mathrm{CC}$ & $4 \quad(1.9)$ & $0 \quad(0.0)$ & $0.182(0.01-3.54)$ & & - \\
\hline CT/AA & $81 \quad(39.1)$ & $26 \quad(27.4)$ & $0.530(0.27-1.05)$ & 0.281 & $(0.07-1.19)$ \\
\hline $\mathrm{CT} / \mathrm{AC}$ & $25(12.1)$ & $18 \quad(18.9)$ & $1.190(0.54-2.64)$ & 0.726 & $(0.17-3.07)$ \\
\hline $\mathrm{TT} / \mathrm{AA}$ & $30 \quad(14.5)$ & 11 (11.6) & $0.606(0.26-1.44)$ & 0.146 & $(0.02-1.00)$ \\
\hline Total & $207(100.0)$ & $95(100.0)$ & & & \\
\hline
\end{tabular}

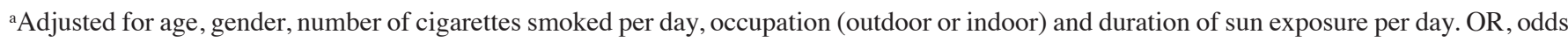
ratio; $\mathrm{CI}$, confidence interval; AOR, adjusted odds ratio.

Table II. Polymorphisms of MTHFR 677C $>$ T and MTHFR 1298A >C in basal cell carcinoma.

\begin{tabular}{|c|c|c|c|c|}
\hline Genotype & Controls (\%) & Cases $(\%)$ & OR $(95 \% \mathrm{CI})$ & $\operatorname{AOR}(95 \% \mathrm{CI})^{\mathrm{a}}$ \\
\hline \multicolumn{5}{|l|}{$677 \mathrm{C}>\mathrm{T}$} \\
\hline $\mathrm{CC}$ & $71 \quad(34.3)$ & $35 \quad(35.0)$ & - & - \\
\hline $\mathrm{CT}$ & $106 \quad(51.2)$ & $49 \quad(49.0)$ & $0.938(0.55-1.59)$ & $0.676(0.30-1.55)$ \\
\hline $\mathrm{TT}$ & $30 \quad(14.5)$ & $16 \quad(16.0)$ & $1.082(0.52-2.24)$ & $0.566(0.17-1.84)$ \\
\hline $\mathrm{CT}+\mathrm{TT}$ & $136(65.7)$ & $65 \quad(65.0)$ & $0.970(0.59-1.60)$ & $0.675(0.31-1.45)$ \\
\hline \multicolumn{5}{|l|}{$1298 \mathrm{~A}>\mathrm{C}$} \\
\hline AA & $149(72.0)$ & $79 \quad(79.0)$ & - & - \\
\hline $\mathrm{AC}$ & $54 \quad(26.1)$ & $20 \quad(20.0)$ & $0.699(0.39-1.25)$ & $0.480(0.18-1.26)$ \\
\hline $\mathrm{CC}$ & $4 \quad(1.9)$ & $1 \quad(1.0)$ & $0.472(0.05-4.29)$ & $0.232(0.01-6.11)$ \\
\hline $\mathrm{AC}+\mathrm{CC}$ & $58 \quad(28.0)$ & $21 \quad(21.0)$ & $0.683(0.39-1.21)$ & $0.450(0.18-1.16)$ \\
\hline \multicolumn{5}{|c|}{$677 \mathrm{C}>\mathrm{T} / 1298 \mathrm{~A}>\mathrm{C}$} \\
\hline CC/AA & 38 (18.4) & $24 \quad(24.0)$ & - & - \\
\hline CC/AC & $29(14.0)$ & $10 \quad(10.0)$ & $0.546(0.23-1.32)$ & $0.206(0.03-1.23)$ \\
\hline $\mathrm{CC} / \mathrm{CC}$ & $4 \quad(1.9)$ & $1 \quad(1.0)$ & $0.396(0.04-3.76)$ & - \\
\hline $\mathrm{CT} / \mathrm{AA}$ & $81 \quad(39.1)$ & $39 \quad(39.0)$ & $0.762(0.40-1.44)$ & $0.399(0.14-1.11)$ \\
\hline $\mathrm{CT} / \mathrm{AC}$ & $25 \quad(12.1)$ & $10 \quad(10.0)$ & $0.633(0.26-1.55)$ & $0.295(0.05-1.61)$ \\
\hline $\mathrm{TT} / \mathrm{AA}$ & $30 \quad(14.5)$ & $16 \quad(16.0)$ & $0.844(0.38-1.87)$ & $0.350(0.09-1.32)$ \\
\hline Total & $207(100.0)$ & $100(100.0)$ & & \\
\hline
\end{tabular}

${ }^{a}$ Adjusted for age, gender, no. of cigarettes per day, occupation and duration of sun exposure per day. OR, odds ratio; CI, confidence interval; AOR, adjusted odds ratio. 
Table III. Polymorphisms of the TS 3'-UTR 14946 bp insertion/deletion in squamous cell carcinoma and basal cell carcinoma.

\begin{tabular}{|c|c|c|c|c|}
\hline Genotype & Controls (\%) & Cases $(\%)$ & OR $(95 \% \mathrm{CI})$ & $\operatorname{AOR}(95 \% \mathrm{CI})^{\mathrm{a}}$ \\
\hline \multicolumn{5}{|l|}{ SCC } \\
\hline $0 \mathrm{bp} / 0 \mathrm{bp}$ & 96 (46.6) & 39 (41.9) & - & - \\
\hline $0 \mathrm{bp} / 6 \mathrm{bp}$ & $99 \quad(48.1)$ & $53 \quad(57.0)$ & $1.318(0.80-2.17)$ & $1.970(0.50-2.87)$ \\
\hline $6 \mathrm{bp} / 6 \mathrm{bp}$ & $11 \quad(5.3)$ & $1 \quad(1.1)$ & $0.224(0.03-1.79)$ & $2.058(0.17-25.40)$ \\
\hline $0 \mathrm{bp} / 6 \mathrm{bp}+6 \mathrm{bp} / 6 \mathrm{bp}$ & $110 \quad(53.4)$ & $54 \quad(58.1)$ & $1.208(0.74-1.98)$ & $1.234(0.52-2.95)$ \\
\hline \multicolumn{5}{|l|}{$\mathrm{BCC}$} \\
\hline $0 \mathrm{bp} / 0 \mathrm{bp}$ & 96 (46.6) & $28 \quad(28.0)$ & - & - \\
\hline $0 \mathrm{bp} / 6 \mathrm{bp}$ & $99 \quad(48.1)$ & $65 \quad(65.0)$ & $2.251(1.33-3.80)$ & $2.821(1.21-6.58)$ \\
\hline $6 \mathrm{bp} / 6 \mathrm{bp}$ & $11 \quad(5.3)$ & $7 \quad(7.0)$ & $2.182(0.77-6.16)$ & $7.539(1.10-51.66)$ \\
\hline $0 b p / 6 b p+6 b p / 6 b p$ & $110 \quad(53.4)$ & $72 \quad(72.0)$ & $2.244(1.34-3.76)$ & $3.079(1.33-7.12)$ \\
\hline Total & $206(100.0)$ & $100(100.0)$ & & \\
\hline
\end{tabular}

${ }^{a}$ Adjusted for age, gender, number of cigarettes smoked per day, occupation and duration of sun exposure per day. SCC, squamous cell carcinoma; BCC, basal cell carcinoma; OR, odds ratio; CI, confidence interval; AOR, adjusted odds ratio.

Table IV. Combinations of MTHFR 677C>T, 1298A>C and the TS 3'-UTR 14946 bp insertion/deletion in basal cell carcinoma.

\begin{tabular}{|c|c|c|c|c|}
\hline Genotype & Controls $(\%)$ & Cases $(\%)$ & OR $(95 \% \mathrm{CI})$ & $\operatorname{AOR}(95 \% \mathrm{CI})^{\mathrm{c}}$ \\
\hline \multicolumn{5}{|c|}{ MTHFR $677 \mathrm{C}>\mathrm{T} / T S 6 \mathrm{bp}$ ins/del } \\
\hline $\mathrm{CC} / 6 \mathrm{bp}(-)^{\mathrm{a}}$ & $34(16.5)$ & $8 \quad(8.0)$ & - & - \\
\hline $\mathrm{CC} / 6 \mathrm{bp}(+)^{\mathrm{b}}$ & $37(18.0)$ & $27 \quad(27.0)$ & $3.101(1.24-7.75)$ & $4.192(0.75-23.48)$ \\
\hline CT/6 bp(-) & $51 \quad(24.8)$ & $14(14.0)$ & $1.167(0.44-3.08)$ & $0.374(0.06-2.46)$ \\
\hline $\mathrm{CT} / 6 \mathrm{bp}(+)$ & $54 \quad(26.2)$ & $35 \quad(35.0)$ & $2.755(1.14-6.64)$ & $2.809(0.68-11.57)$ \\
\hline TT/6 bp(-) & $11 \quad(5.3)$ & $6 \quad(6.0)$ & $2.318(0.66-8.16)$ & $54.750(0.40-7.46)$ \\
\hline $\mathrm{TT} / 6 \mathrm{bp}(+)$ & $19 \quad(9.2)$ & $10(10.0)$ & $2.237(0.76-6.63)$ & $1.204(0.20-7.40)$ \\
\hline \multicolumn{5}{|c|}{ MTHFR $1298 \mathrm{~A}>\mathrm{C} / T S 6 \mathrm{bp}$ ins/del } \\
\hline AA/6 bp(-) & $71(34.5)$ & $23 \quad(23.0)$ & - & - \\
\hline $\mathrm{AA} / 6 \mathrm{bp}(+)$ & 77 (37.4) & $56 \quad(56.0)$ & $2.245(1.25-4.02)$ & $3.288(1.24-8.73)$ \\
\hline $\mathrm{AC} / 6 \mathrm{bp}(-)$ & $23(11.2)$ & $4 \quad(4.0)$ & $0.537(0.17-1.72)$ & $0.509(0.08-3.20)$ \\
\hline $\mathrm{AC} / 6 \mathrm{bp}(+)$ & $31 \quad(15.0)$ & $16(16.0)$ & $1.593(0.74-3.42)$ & $1.703(0.38-7.69)$ \\
\hline $\mathrm{CC} / 6 \mathrm{bp}(-)$ & $2 \quad(1.0)$ & $1 \quad(1.0)$ & $1.543(0.13-17.83)$ & - \\
\hline $\mathrm{CC} / 6 \mathrm{bp}(+)$ & $2 \quad(1.0)$ & $0 \quad(0.0)$ & $0.609(0.03-13.14)$ & - \\
\hline Total & $206(100.0)$ & $100(100.0)$ & & \\
\hline
\end{tabular}

a $6 \mathrm{bp}(-)$ represents $0 \mathrm{bp} / 0 \mathrm{bp} .{ }^{\mathrm{b}} 6 \mathrm{bp}(+)$ represents $0 \mathrm{bp} / 6 \mathrm{bp}$ and $6 \mathrm{bp} / 6 \mathrm{bp} .{ }^{\mathrm{c}}$ Adjusted for age, gender, number of cigarettes smoked per day, occupation and duration of sun exposure per day. OR, odds ratio; CI, confidence interval; AOR, adjusted odds ratio.

However, the combined 677CC/6 bp(+) and 677CT/6 bp(+) genotypes of the MTHFR $677 \mathrm{C}>\mathrm{T}$ and TS $6 \mathrm{bp}$ ins/del polymorphisms were found to increase the risk for BCC when adjusted for age, gender, smoking history, occupation and duration of sun exposure (Table IV). When the MTHFR 677C >T and TS 6 bp ins/del polymorphisms were combined, the 1298AA/6 bp(+) combined genotype was responsible for elevating the risk of cancer development by $>3$-fold (AOR=3.288, 95\% CI 1.24-8.73). However, the combined genotypes of the MTHFR $677 \mathrm{C}>\mathrm{T}$ and TS 6 bp ins/del polymorphisms did not show any association with SCC.

\section{Discussion}

In the present study, the MTHFR $677 \mathrm{C}>\mathrm{T}$ polymorphism did not significantly contribute to the development of SCC when adjusted to conventional factors such as age, gender, smoking history, occupation and duration of sun exposure. However, the 677CT and 677TT genotypes tended to suppress the development of SCC. When only age was taken into consideration (data not shown), both a homozygous mutation (677TT) and an overall genotype (677CT+TT) of the MTHFR $677 \mathrm{C}>\mathrm{T}$ polymorphism showed a statistically significant difference 
(OR=0.334, 95\% CI 0.12-0.92; OR=0.343, 95\% CI 0.13-0.94, respectively). The MTHFR $677 \mathrm{TT}$ genotype (OR=0.343, 95\% CI 0.13-0.94) upon adjustment for age and gender as well as the $677 \mathrm{CT}+\mathrm{TT}$ genotype (OR=0.437, 95\% CI 0.20-0.94) upon adjustment for age, gender and smoking history were associated with a significantly reduced risk of cancer. This suggests that the MTHFR $677 \mathrm{C}>\mathrm{T}$ polymorphism has a very low probability of inducing carcinogenesis. Concerning the MTHFR 1298A>C polymorphism in SCC of the skin, there was a 2-fold increased risk of cancer development associated with the 1298AC genotype $(\mathrm{OR}=2.208$, 95\% CI 1.09-4.48) upon adjustment for age, and with the 1298AC genotype and overall genotype of 1298AC+CC $(\mathrm{OR}=2.267,95 \%$ CI 1.11-4.63; OR $=2.034,95 \%$ CI 1.01-4.09) upon adjustment for age and gender, and for age, gender and smoking history $(\mathrm{OR}=2.381,95 \% \mathrm{CI} 1.71-5.26)$.

Due to the lack of studies on the MTHFR $677 \mathrm{C}>\mathrm{T}$ and MTHFR 1298A>C polymorphisms in SCC of the skin, it is not possible to make direct comparisons. There is, however, a study conducted among Hispanic Americans with regards to SCC of the head and neck (31). This study documented that the 1298AC and 1298CC genotypes and the overall genotype (1298AC+CC) significantly suppressed the occurrence of cancer $(\mathrm{AOR}=0.69,0.28$ and $0.65 ; 95 \%$ CI $0.5-0.9,0.1-0.6$ and $0.5-0.8$, respectively) upon adjustment for age, gender and smoking and drinking history.

When studying crude OR, the 677CT genotype of the MTHFR $677 \mathrm{C}>\mathrm{T}$ polymorphism appeared to increase the risk of cancer development, though without statistical significance. Upon categorizing subjects with less than one mutation and those with two or more mutations, the possibility of cancer development increased by 2- to 3-fold in each of the cases where there was an increase in age, smoking and drinking, while all the conventional risk factors combined showed no statistical significance. Overall, the MTHFR $677 \mathrm{C}>\mathrm{T}$ polymorphism had a tendency to inhibit carcinogenesis in SCC of the skin, in contrast to the MTHFR 1298A>C polymorphism, which tended to promote carcinogenesis. It is necessary to consider the difference between the location of cancer occurrence as well as the ethnicity of the patients.

Through studies of single nucleotide polymorphisms (SNPs), enzymes that are involved in the process of base repair, such as X-ray repair cross-complementing groups 1 $(X R C C 1)$, have been reported to be associated with the development of BCC (32-36).

With regards to $\mathrm{BCC}$, the MTHFR $677 \mathrm{C}>\mathrm{T}$ and MTHFR $1298 \mathrm{~A}>\mathrm{C}$ polymorphisms did not show any statistical significance in this study, but both had the tendency to supress the occurrence of BCC by 35 and $60 \%$, respectively. The $1298 \mathrm{CC}$ genotype of the MTHFR $1298 \mathrm{~A}>\mathrm{C}$ polymorphism in particular provided more than $70 \%$ inhibition compared to the 1298AA normal genotype. Taken together, the results of the present study reflect the suppressive effects of the $C$ allele of the MTHFR 1298A>C polymorphism on cancer development. Overall, the 1298AC+CC genotype of the MTHFR $1298 \mathrm{~A}>\mathrm{C}$ polymorphism, upon adjustment for duration of sun exposure, showed a significance of $50 \%(\mathrm{OR}=0.48,95 \% \mathrm{CI}$ $0.234-0.985$ ) in suppressing carcinogenesis compared to the 1298AA genotype.

In a study performed on the correlation between the MTHFR $677 \mathrm{C}>\mathrm{T}$ polymorphism and the development of
BCC among a Swedish population, the 677TT genotype conferred an increased risk of BCC development compared to the $677 \mathrm{CC}$ genotype $(\mathrm{OR}=1.67,95 \% \mathrm{CI} 1.13-2.47)$. This indicated that the $T$ allele was associated with an elevated risk of cancer development. The $C$ allele of the MTHFR 1298A >C polymorphism was associated with the occurrence of cancer, though without statistical significance (37). Investigation into the MTHFR $677 \mathrm{C}>\mathrm{T}$ and MTHFR $1298 \mathrm{~A}>\mathrm{C}$ polymorphisms in cases with BCC of the skin among Swedish and Finnish populations revealed no statistical significance (36). However, a combination analysis of the 677TT genotype of the MTHFR $677 \mathrm{C}>\mathrm{T}$ polymorphism and of the AA genotype of the MTHFR 1298A $>\mathrm{C}$ polymorphism indicated that the mutations (677TT/1298AA) increased the likelihood of cancer development (OR=1.94, 95\% CI 0.96-3.89, $\mathrm{p}<0.07)$.

In the present study, statistical significance was not obtained in the combination analysis of the MTHFR $677 \mathrm{C}>\mathrm{T}$ and MTHFR 1298A>C polymorphisms, but the combined genotypes $677 \mathrm{CC}+1298 \mathrm{AC}, 677 \mathrm{CT}+1298 \mathrm{AA}$ and 677TT+1298AA $(\mathrm{AOR}=0.206,0.399$ and $0.350 ; 95 \%$ CI $0.03-1.23,0.14-1.11$ and $0.09-1.32$, respectively) tended to diminish the risk of cancer development by more than $60 \%$ as compared to the $677 \mathrm{CC}+1298 \mathrm{AA}$ genotype. The combination of the MTHFR 677C $>$ T and MTHFR 1298A >C mutations exerted a stronger suppressive effect; thus, coexistence of the two mutations is postulated to suppress cancer development to a greater degree. The MTHFR 1298A $>$ C mutation demonstrated a greater suppressive effect; hence, it can be expected that the occurrence of cancer will be increasingly inhibited in individuals with both mutations. Furthermore, it can be presumed that the MTHFR 1298A allele exerted a stronger suppressive effect; hence, a homozygous variant would act as a stronger inhibitor of carcinogenesis. The same data is obtained in terms of OR. However, these results are contradictory to those obtained in Swedish and Finnish populations, indicating that the $C$ allele of the MTHFR 1298A >C polymorphism exerts the opposite effect in Koreans.

Studies performed on the link between hepatocellular carcinoma and the MTHFR 677C $>\mathrm{T}$, MTHFR 1298A $>\mathrm{C}$ and TS 3'-UTR 6 bp ins/del polymorphisms among individuals from Los Angeles, California and Guangxi, China did not exhibit statistical significance. However, the 677TT and 1298CC genotypes exerted 30-50\% suppressive effects compared to their normal counterparts. Homozygous variants (677TT and 1298CC) had a tendency to suppress carcinogenesis, contrary to a case with only one mutation, which did not show any difference in the risk of cancer development. Despite a discrepancy in the type of cancer, the above results correlate entirely to those drawn in the present study.

This study is the first to report the link between TS and the development of skin cancer. Thymidylate, as a rate-limiting nucleotide, is involved in the process of DNA synthesis and repair, and thus must be present in sufficient quantities to minimize the misincorporation of uracil into DNA, chromosome breakage and fragile site induction. The $0 \mathrm{bp} / 0 \mathrm{bp}$ genotype has been reported in several studies to diminish the risk of the development of spina bifida, lung cancer, non-Hodgkin's lymphoma, breast cancer and malignant melanoma.

In the present study, the $6 \mathrm{bp} / 6 \mathrm{bp}$ genotype of the TS 3'-UTR $6 \mathrm{bp}$ ins/del polymorphism failed to produce statis- 
tically significant differences as compared to the control group, although it showed an inclination to raise the risk of the development of SCC. With regards to BCC, the mutations were associated with an elevated risk of cancer. However, we were unable to produce statistically meaningful data due to the small number of homozygous variants within the $\mathrm{BCC}$ and control groups.

TS 3'-UTR 6 bp ins/del polymorphism analyses performed on a group of healthy individuals and a group of hepatocellular carcinoma patients (among them inhabitants of Los Angeles, California and Guangxi, China) showed that the $0 \mathrm{bp} / 6 \mathrm{bp}$ and $0 \mathrm{bp} / 6 \mathrm{bp}$ genotypes suppressed carcinogenesis as compared to the $6 \mathrm{bp} / 6 \mathrm{bp}$ genotype. These results demonstrate that the $6 \mathrm{bp}$ insertion contributed towards an increased risk of cancer development. Our data show that the 6 bp genotype was associated with a 2- to 3-fold increased risk of cancer. The Han population (Asians) was also found to be liable to an increased risk of cancer development. The 0 bp genotype of $T S$ produced an enzyme with diminished functional capacity, leading to the accumulation of 5,10-methylenetetrahydrofolate. This consequently activated the synthesis of thymidylate. Such a phenomenon secondarily provides protective effects by minimizing the misincorporation of uracil and double-strand breaks (26).

In the present study, a combination analysis of the MTHFR and TS 3'-UTR polymorphisms did not provide any statistically significant results. Regarding SCC, however, the combined genotypes 677TT/6 bp of TS 3'-UTR afforded a $70 \%$ suppressive effect (AOR=1.776, 95\% CI 0.41-7.63) compared to the genotype 677TT/0 bp. The 677TT genotype of the MTHFR $677 \mathrm{C}>\mathrm{T}$ polymorphism is assumed to exert a stronger suppressive effect than the $6 \mathrm{bp}$ insertion of the TS 3'-UTR polymorphism. On the other hand, the combination of $1298 \mathrm{AC} / 6 \mathrm{bp}$ had a tendency to produce a 2 -fold increase in carcinogenesis (AOR=2.646, 95\% CI 0.71-9.83) compared to a homozygous variant or $0 \mathrm{bp}$, presumably owing to both the mutations acting towards increasing the risk.

The combined genotypes $677 \mathrm{CC} / 6 \mathrm{bp}$ and $677 \mathrm{CT} / 6 \mathrm{bp}$ in $\mathrm{BCC}$ had a statistically significant tendency to increase the risk of cancer development. The combination of the homozygous variant (677TT) and $6 \mathrm{bp}$, when juxtaposed with the combination of the heterozygous variant (677CT) and $6 \mathrm{bp}(-)$, displayed a 3-fold increase in the likelihood of carcinogenesis. We therefore postulated that the alleles 6777 and $6 \mathrm{bp}$ exerted a synergistic effect. The combined genotype 1298AA/6 bp(+) of the MTHFR $1298 \mathrm{~A}>\mathrm{C}$ and 3'-UTR ins/del polymorphisms had an AOR of 3.288 with a $95 \%$ CI of $1.24-$ 8.73 , thus increasing the risk of cancer development by 3 -fold (Table IV). It is assumed that the combination genotypes, in the absence of the suppressive action of the $1298 \mathrm{C}$ allele, exerted a synergistic effect, increasing the risk of cancer by 6-fold in the case of the combined genotype 1298AC and $6 \mathrm{bp}(-)$. The suppressive action of the $C$ allele and promoting action of the $6 \mathrm{bp}$ insertion were also assumed to be relatively stronger.

Further studies taking into account the variable number of tandem repeats and the G/C SNP of the TS gene are required. Environmental factors that were excluded in the present study, such as folic acid intake, also warrant examination in relation to carcinogenesis of the skin. Such studies may form the basis on which may be built the possibility of accurate identification of groups manifesting risk factors for the early diagnosis of cancer.

Conclusively, although there were no associations between the MTHFR and TS polymorphisms and patients with skin cancer among Korean individuals, a relationship between the type of skin cancer and the combined genotypes was demonstrated to exist. To the best of our knowledge, this is to date the first study on the significant association between the $T S$ polymorphism and skin cancer patients. To obtain more evidence on the association between $T S$ polymorphisms and skin cancer, population studies conducted among other ethnicities are required. Furthermore, the biochemical mechanisms of the MTHFR and TS polymorphisms require analysis.

\section{Acknowledgements}

This study was supported by a grant from the Kyung Hee University in 2009 (KHU-20090603).

\section{References}

1. Mohrenweiser HW, Xi T, Vázquez-Matías J and Jones IM: Identification of 127 amino acid substitution variants in screening 37 DNA repair genes in humans. Cancer Epidemiol Biomarkers Prev 11: 1054-1064, 2002.

2. Pogribny IP, Muskhelishvili L, Miller BJ and James SJ: Presence and consequence of uracil in preneoplastic DNA from folate/ methyl-deficient rats. Carcinogenesis 18: 2071-2076, 1997.

3. Dianov GL, Timchenko TV, Sinitsina OI, Kuzminov AV, Medvedev OA and Salganik RI: Repair of uracil residues closely spaced on the opposite strands of plasmid DNA results in double strand break and deletion formation. Mol Gen Genet 225: 448-452, 1991.

4. Robien K and Ulrich CM: 5,10-methylenetetrahydrofolate reductase polymorphisms and leukemia risk: a HuGE minireview. Am J Epidemiol 157: 571-582, 2003.

5. Frosst $\mathrm{P}$, Blom HJ and Milos R: A candidate genetic risk factor for vascular disease: a common mutation in methylenetetrahydrofolate reductase. Nat Genet 10: 111-113, 1995.

6. Rozen R: Genetic predisposition to hyperhomocysteinemia: deficiency of methylenetetra hydrofolate reductase (MTHFR). Thromb Haemost 78: 523-526, 1997.

7. Weisberg I, Tran P, Chritensen B, Sibani S and Rozen R: A second genetic polymorphism in methylenetetrahydrofolate reductase (MTHFR) associated with decreased enzyme activity. Mol Genet Metab 64: 169-172, 1998.

8. McCully KS: Vascular pathology of homocysteinemia: implication for the pathogenesis of arteriosclerosis. Am J Pathol 56: $111-128,1969$.

9. Fodinger M, Wagner OF, Horl WH and Sunderplassman G: Recent insights into the molecular genetics of the homocysteine metabolism. Kidney Int Suppl 78: S238-S242, 2001

10. Jakubowski H, Zhang L, Bardequez A and Aviv A: Homocysteine thiolactone and protein homocysteinylation in human endothelial cells: implication for atherosclerosis. Circ Res 87: 45-47, 2000.

11. Wang LD, Guo RF, Fan ZM, He X, Gao SS, Guo HQ, Matsuo K, Yin LM and Li JL: Association of methylenetetrahydrofolate reductase and thymidylate synthase promoter polymorphisms with genetic susceptibility to esophageal and cardia cancer in a Chinese high-risk population. Dis Esophagus 18: 177-184, 2005.

12. Song C, Xing D, Tan W, Wei Q and Lin D: Methylenetetrahydrofolate reductase polymorphisms increase risk of esophageal squamous cell carcinoma in a Chinese population. Cancer Res 61: 3272-3275, 2001.

13. Park KS, Mok JW and Kim JC: The $677 \mathrm{C} \rightarrow \mathrm{T}$ mutation in $5,10-$ methylenetetrahydrofolate reductase and colorectal cancer risk. Genet Test 3: 233-236, 1999.

14. Skibola CF, Smith MT, Kane E, Roman E, Rollinson S, Cartwright RA and Morgan G: Polymorphisms in the methylenetetrahydrofolate reductase gene are associated with susceptibility to acute leukemia in adults. Proc Natl Acad Sci USA 96: 12810-12815, 1999. 
15. Kaneda S, Takeishi K, Ayusawa D, Shimizu K, Seno T and Altman S: Role in translation of a triple tandemly repeated sequence in the 5'-untranslated region of human thymidylate synthase mRNA. Nucl Acids Res 15: 1259-1270, 1987.

16. Hori $T$, Ayusawa D, Shimizu K, Koyama $H$ and Seno $T$ : Chromosome breakage induced by thymidylate stress in the thymidylate synthase-negative mutants of mouse FM3A cells. Cancer Res 44: 703-709, 1984.

17. Duthie SJ: Folic acid deficiency and cancer: mechanisms of DNA instability. Br Med Bull 55: 578-592, 1999.

18. Khanna KK and Jackson SP: DNA double-strand breaks: signaling, repair and the cancer connection. Nat Genet 27: 247-254, 2001

19. Maeng JH and Yoon JB: The human PTFgamma/SNAP43 gene: structure, chromosomal location, and identification of a VNTR in 5'-UTR. J Biochem 14: 23-27, 1998.

20. Goto Y, Yue L, Yokoi A, Nishimura R, Uehara T, Koizumi S and Saikawa Y: A novel single-nucleotide polymorphism in 3'-untranslated region of the human dihydrofolate reductase gene with enhanced expression. Clin Cancer Res 7: 1952-1956, 2001.

21. Mill J, Asherson P, Browes C, D'Souza U and Craig I: Expression of the dopamine transporter gene is regulated by the 3' UTR VNTR: evidence from brain and lymphocytes using quantitative RT-PCR. Am J Med Genet 114: 975-979, 2002.

22. Moor CH, Meijer H and Lessenden S: Mechanisms of translational control by the 3' UTR in development and differentiation. Semin Cell Dev Biol 16: 49-58, 2005.

23. Marsh S, McKay JA, Cassidy J and McLeod HL: Polymorphism in the thymidylate synthase promoter enhancer region in colorectal cancer. Int J Oncol 19: 383-386, 2001.

24. Mandola MV, Stoehlmacher J, Zhang W, Groshen S, Yu MC, Iqbal S, Lens HJ and Ladner RD: A 6 bp polymorphism in the thymidylate syntase gene causes message instability and is associated with decreased intratumoral TS mRNA levels. Pharmacogenetics 14: 319-327, 2004.

25. Ulrich CM, Bigler J, Velicer CM, Greene EA, Farin FM and Potter JD: Searching expressed sequence tag databases: discovery and confirmation of a common polymorphisms in thymidylate syntase gene. Cancer Epidermiol Biomarkers Prev 9: $1381-1385,2000$.

26. Blount BC, Mack MM, Wehr CM, Macgregor JT, Hiatt RA, Wang G, Wickramasinghe SN, Everson RB and Ames BN: Folate deficiency causes uracil misincorporation into human DNA and chromosome breakage: implications for cancer and neuronal damage. Proc Natl Acad Sci USA 94: 3290-3295, 1997.

27. Ulrich CM, Bigler J, Bostrick R, Fosdick L and Potter JD: Thymidylate synthase promoter polymorphisms, interaction with folate intake, and risk of colorectal adenoma. Cancer Res 62: 3361-3364, 2002.
28. Lightfoot TJ, Skibola CF, Willett EV, Skibola DR, Allan JM and Coppede F: Risk of non-Hodgkin lymphoma associated with polymorphisms in folate-metabolizing genes. Cancer Epidemiol Biomarkers Prev 14: 2999-3003, 2005.

29. Zhai X, Gao J, Hu Z, Tang J, Qin J and Wang S: Polymorphisms in thymidylate synthase gene and susceptibility to breast cancer in a Chinese population: a case-control analysis. BMC Cancer 6: $138,2006$.

30. Kealey C, Brown KS, Woodside JV, Young I, Murray L, Boreham CA, McNulty H, Strain JJ, McPartlin J, Scott JM and Whitehead AS: A common insertion/deletion of the thymidylate synthase (TYMS) gene is a determinant of red blood cell folate and homocysteine concentrations. Hum Genet 116: 347-353, 2005.

31. Neumann AS, Lyons HJ, Shen H, Liu Z, Shi Q, Sturgis EM, Shete S, Spitz MR, EI-Naggar A, Hong WK and Wei Q: Methylenetetrahydrofolate reductase polymorphisms and risk of squamous cell carcinoma of the head and neck: a case-control analysis. Int J Cancer 115: 131-136, 2005.

32. Nelson HH, Kelsey KT, Mott LA and Karagas MR: The XRCC1 Arg399Gln polymorphism, sunburn, and, non-melanoma skin cancer: evidence of gene environment interaction. Cancer Res 62: 152-155, 2002.

33. Vogel U, Hedayati M, Dybdahl M, Grossman L and Nexo BA: Polymorphisms of the DNA repair gene XPD: correlations with risk of basal cell carcinoma revisited. Carcinogenesis 22: 899-904, 2001

34. Winsey SL, Haldar NA, Marsh HP, Bunce M, Marshall SE, Harris AL, Wojnarowska F and Welsh KI: A variant within the DNA repair gene XRCC3 is associated with the development of melanoma skin cancer. Cancer Res 60: 5612-5616, 2000

35. Zhang Z, Liu W, Jia X, Gao Y, Hemminki K and Lindholm B: Use of pyrosequencing to detect clinically relevant polymorphisms of genes in basal cell carcinoma. Clin Chim Acta 342: $137-143,2004$.

36. Festa F, Kumar R, Sanyal S, Unden B, Nordfors L, Lindholm B, Snellman E, Schalling M, Försti A and Hemminki K: Basal cell carcinoma and variants in genes coding for immune response, DNA repair, folate and iron metabolism. Mutat Res 574: 105-111, 2005.

37. Zhang J, Cui Y, Kuang G, Li Y, Wang N, Wang R, Guo W, Wen D, Wei L, Yu F and Wang S: Association of the thymidylate synthase polymorphisms with esophageal squamous cell carcinoma and gastric cardiac adenomacarcinoma. Carcinogenesis 25: 2479-2485, 2004. 